\title{
Immunohistochemical and virological features of HTLV-1-associated myosites: a study of 13 patients from West Indies and Africa
}

\author{
Marion Desdouits', Olivier Cassarr, Thierry Maisonobe², Alexandra Desrames ${ }^{1}$, Achille Aouba $^{3}$, Olivier Hermine ${ }^{3}$, \\ Jacqueline Mikol ${ }^{4}$, Marc Polivka ${ }^{4}$, Isabelle Penisson-Besnier ${ }^{5}$, Pascale Marcorelles ${ }^{6}$, Fabien Zagnoli', Thomas Papo ${ }^{8}$, \\ Arnaud Lacour ${ }^{9}$, Zahir Amoura ${ }^{2}$, Julien Haroche ${ }^{2}$, Patrick Chérin², Antonio Texeira ${ }^{2}$, Anne-Sophie Morin ${ }^{10}$, \\ Franck Mortreux ${ }^{11}$, Eric Wattel ${ }^{11}$, Michel Huerre ${ }^{12}$, Marie-Christine Cumont ${ }^{12}$, Huot Khun ${ }^{12}$, Sylviane Bassot ${ }^{1}$, \\ Sandra Martin-Latil ${ }^{1}$, Graham Taylor ${ }^{13}$, Antoine Gessain ${ }^{1}$, Simona Ozden ${ }^{1}$, Pierre-Emmanuel Ceccaldi ${ }^{1,14^{*}}$
}

From 15th International Conference on Human Retroviruses: HTLV and Related Viruses

Leuven and Gembloux, Belgium. 5-8 June 2011

\section{Background}

HTLV-1 is associated with the onset of various inflammatory diseases such as HTLV-1 Associated Myelopathy / Tropical Spastic Paraparesis, uveitis, infective dermatitis or inflammatory myopathies. Here, we aimed to get new insights into the pathogenesis of HTLV-1 associated inflammatory myopathies (HAIM) by studying muscle biopsy specimens and blood samples from 13 HAIM patients.

\section{Results}

Mean age of patients was 52.2 years. 7 patients suffered from polymyositis (PM), and 6, from inclusion body myositis (IBM). Histopathological changes were mild to moderate in most patients. Tumor necrosis factor (TNF)-alpha and myeloid dendritic cells were detected in several patients' biopsies, and Human Leukocyte Antigen (HLA)-ABC, HLA-DR, and matrix metalloproteinase (MMP-2, -9), in most of them. Perforin was frequently detected but there were no apoptotic myonuclei. By means of in situ hybridization, we detected rare HTLV-1 infected infiltrating cells in the muscle tissue of 4 patients. The virus belonged to the cosmopolitan A subtype, transcontinental subgroup. Plasma anti-HTLV1 antibodies titers were high, but the proviral load was not elevated when compared to asymptomatic HTLV-1

\footnotetext{
* Correspondence: pierre-emmanuel.ceccaldi@pasteur.fr

'Epidemiology and Physiopathology of Oncogenic Viruses Unit, CNRS 3015, Pasteur Institute, Paris, France

Full list of author information is available at the end of the article
}

carriers. Myositis-associated autoantibodies were found in patients with HAIM as well as in HTLV-1 infected controls without HAIM, whereas IFN-gamma plasma levels were elevated in HAIM patients.

\section{Conclusions}

We describe 13 cases of HTLV-1 associated myositis, which show the classical anatomopathologic features of idiopathic myositis, with moderate muscle inflammation and atrophy. Proviral load was not elevated, but antiHTLV-1 antiboides titer and IFN-gamma plasma levels were raised.

\section{Author details}

'Epidemiology and Physiopathology of Oncogenic Viruses Unit, CNRS 3015, Pasteur Institute, Paris, France. ${ }^{2}$ Pitié Salpêtrière Hospital, Paris, France. ${ }^{3}$ Necker Hospital, Paris, France. ${ }^{4}$ Lariboisière Hospital, Paris, France. ${ }^{5}$ University Hospital Center, Angers, France. ${ }^{6}$ University Hospital Center, Brest, France. ${ }^{7}$ Clermont Tonnerre Army Hospital, Brest, France. ${ }^{8}$ Bichat Hospital, Paris, France. ${ }^{9}$ University Hospital Center, Lille, France. ${ }^{10}$ Beaujon Hospital, Clichy, France. ${ }^{11}$ Oncology and Biotherapies Unit, Lyon University, Lyon, France. ${ }^{12}$ Histotechnolgy and Histopathology Unit, Pasteur Institute, Paris, France. ${ }^{13}$ Faculty of Medicine, Imperial College, London, UK. ${ }^{14}$ Paris 7 University, Paris, France.

Published: 6 June 2011

\section{doi:10.1186/1742-4690-8-S1-A41}

Cite this article as: Desdouits et al:: Immunohistochemical and virological features of HTLV-1-associated myosites: a study of 13 patients from West Indies and Africa. Retrovirology 2011 8(Suppl 1):A41. 